\title{
Use of maternal health care as a predictor of postpartum contraception in Nigeria
}

\author{
Ambrose Akinlo ${ }^{1}$, Adeleke Bisiriyu ${ }^{1}$, and Olapeju Esimai ${ }^{2}$ \\ ${ }^{1}$ Department of Demography and Social Statistics, Obafemi Awolowo University, Ile-Ife, Nigeria \\ ${ }^{2}$ Department of Community Health, Obafemi Awolowo University, Ile-Ife, Nigeria
}

\begin{abstract}
This study examines the relationship between the utilisation of maternal health care and the postpartum use of contraception in Nigeria. The analysis was based on the data from the Women's Questionnaire and the calendar data from the 2008 Nigeria Demographic and Health Survey (NDHS). Only women whose most recent birth was between January 2003 and one full year before the date of interview in 2008 were included. The use of maternal health care (ANC visits and timing of postnatal check-up) is significantly associated with the use of a modern method of contraception during the postpartum period. Other significant predictors of the postpartum use of a modern method include region, education, the household wealth index, exposure to family planning messages and religion. The findings suggest that contraceptive use among postpartum women will increase substantially if more women use maternal health care services, especially for antenatal care and postnatal care.
\end{abstract}

Keywords: postpartum, contraceptive use, maternal health care

\section{Résumé}

Cette étude examine la relation entre l'utilisation des soins de santé maternelle et de l'utilisation de la contraception post-partum au Nigeria. L'analyse est fondée sur les données du questionnaire à l'intention des femmes et des données de calendrier de l'Enquête Démographique et de Santé 2008 Nigeria (NDHS). Seules les femmes dont la naissance la plus récente était entre Janvier 2003 et une année complète avant la date de l'interview en 2008 ont été inclus. L'utilisation des services de santé maternelle (visites prénatales et le calendrier des postnatal check-up) est significativement associé à l'utilisation d'une méthode moderne de contraception pendant la période post-partum. Autres facteurs prédictifs significatifs de l'utilisation d'une méthode moderne dans la période du post-partum comprennent région, l'éducation, l'indice de richesse des ménages, et l'exposition aux messages de planification familiale. Les résultats suggèrent que l'utilisation de contraceptifs parmi les femmes post-partum augmentera considérablement si plus de femmes utilisent les services de soins de santé maternelle, notamment des soins prénatals et postnatals.

Mots-clés: après l'accouchement, la contraception, les soins de santé maternelle

\section{Introduction}

Postpartum family planning (PPFP) has long been recognised as an important component of maternal health care. Through birth spacing and prevention of high-risk and unwanted pregnancies, PPFP helps women who have recently delivered to avoid exposure to the risks of maternal death. Likewise, the importance of the interplay between maternal health services and use of contraception in the postpartum period has been recognised for decades. For instance, in 1966 the Population Council launched an International Postpartum Programme (IPP) to integrate family planning and maternal and child health services in certain countries (Ringheim 20II). Although the IPP was successful, the Population Council's proposed global plan for integration of maternal and child health services with family planning (Taylor and Berelson 197I) was not realised.

After decades of relegation to the back line in international health priorities, postpartum family planning has again come to the fore of international attention. For example, the London Summit on Family Planning in July 2012 emphasised international prioritisation of PPFP. Major stakeholders at the meeting, including the United States Agency for International Development (USAID), the United Nations Population Fund (UNFPA), the World Bank, Save the Children, and the Bill and Melinda Gates Foundation, to mention only a few, issued a joint statement urging collective action for postpartum family planning. Also, Millennium Development Goal (MDG) 5(b) emphasises universal access to repro-

I. Department of Demography and Social Statistics, Obafemi Awolowo University, lle-lfe, Nigeria

2. Department of Community Health, Obafemi Awolowo University, Ile-Ife, Nigeria Corresponding author: akinloa@oauife.edu.ng; akinlo@gmail.com 
ductive health care, with the aim of increasing the contraceptive prevalence rate, increasing antenatal care coverage, and reducing unmet need for family planning, which includes unmet need among postpartum women. Many women in the postpartum period do not start to use contraception until the return of menstruation, but they become fecund before menstruation returns, and, thus, they are at risk of unwanted pregnancy if sexual activity has resumed (Borda et al. 20 I0). Typically, women's level of unmet need is particularly high in the postpartum period (Ross and Winfrey 200I).

The linkage between the use of maternal health care during pregnancy and the uptake of contraception in the postpartum period has been studied previously. For instance, a study on the relationship between use of antenatal care and use of modern contraception in Bolivia, Egypt, and Thailand found that women's use of health care services during the antenatal and postpartum stages offers an opportunity to counsel them on contraception and to make services available to them. The authors' hypothesis that early exposure to pregnancy-related services can increase a woman's propensity to use modern contraceptives in the postpartum period was also validated by their findings (Zerai and Tsui 200 I).

Guided by the research question: Is women's postpartum contraceptive use associated with their use of maternal health care, this paper seeks to determine the proportion of women in the postpartum period using a contraceptive method and relate the utilisation of maternal health care to contraceptive use in the 12 months following childbirth.

\section{Literature review}

Globally, more than 90 percent of women during the first year postpartum want to either delay or avoid future pregnancies (Ross and Winfrey 200I). An increase in contraceptive use during the postpartum period should substantially reduce rates of maternal and infant mortality by preventing unplanned and unwanted pregnancies and by spacing new pregnancies at least two years after the previous birth (Vernon 2009). Laukaran and Winikoff (1985) laid out the rationale for postpartum contraception: First, women in the postpartum period may be most motivated to avoid pregnancy and thus to use contraception. Second, if women do not initiate contraception immediately after childbirth, they may become pregnant before their next encounter with a health or family planning provider.

Furthermore, integrating family planning into antenatal and postpartum care offers a number of potential benefits-broader cultural acceptability of family planning when presented as a component of maternal and child health services, the fact that women who receive counselling during a facility stay for delivery are more likely to use contraceptives in the postpartum period, and the improved ability of providers to make a more comprehensive assessment of women's reproductive health needs and to respond to those needs and so improve health outcomes. Based on this rationale and the fact that there is strong evidence of the health risks for mother and baby related to short birth intervals, intensive family planning programmes need to be directed toward supplying contraceptives to women during hospitalisation for maternity care (Laukaran and Winikoff 1985). Similarly, there is need to focus on the postpartum period for supplying contraceptives to women.

Nigeria is Africa's most populous country and has the second largest economy on the continent, behind South Africa. The 2006 Population and Housing Census put the country's population at 140 million, with a growth rate of 3.2 percent per annum. The news media in Nigeria, quoting the National Population Commission, have widely reported that the country's population is now more than 167 million; a senior politician, who chairs the Senate Committee on Population and National Identity, confirmed the figure in his speech to mark the 7 billion world population day (Olokor 2012, Lawrence 2012, Lawan 2012). Nigeria is among the world's 10 countries with the largest populations, and its policymakers are becoming increasingly concerned about its demographic profile and population dynamics.

With only three years left to attain MDG 5, statistics on contraceptive prevalence, antenatal care, and unmet need for contraception in Nigeria suggest that the country may not meet the goal. The 2008 NDHS shows that only 10 percent of women are using modern methods; just 58 percent of women received antenatal care from skilled providers; and skilled providers assisted only 39 percent of deliveries (NPC and ICF Macro 2009). In Nigeria, about II percent of pregnancies are unplanned. NPC and ORC Macro (2009) reported that overall, 4 percent of births were unwanted, while 7 percent were mistimed (wanted later) and estimated that if all unwanted births were prevented, the total fertility rate will marginally decline to 5.3 instead of 5.7. The NDHS reports in 2003 and 2008 show that the total fertility rate in Nigeria stagnated at 5.7.

Levels of contraceptive use are low in Nigeria. Although in the 2008 NDHS, 72 percent of all women and 90 percent of all men knew at least one contraceptive method, only 29 percent of currently married women had ever used a family planning method. At the time of the survey, just 15 percent of currently married women were using any contra- 
ceptive method, and only 10 percent were using a modern method-3 percent using injectable, 2 percent each using condoms and the pill, and 3 percent using various other methods. Current use of contraception in Nigeria has increased from 6 percent of currently married women in 1990 to 13 percent in 2003 and 15 percent in 2008 . There has been a corresponding increase in the use of modern contraceptive methods, from 4 percent in 1990 to 8 percent in 2003 to 10 percent in 2008. According to the 2008 NDHS, somewhat more than half of women (58 percent) received antenatal care during their most recent pregnancy from a health professional-23 percent from a doctor, 30 percent from a nurse or midwife, and 5 percent from an auxiliary nurse or midwife. Some 36 percent did not receive any antenatal care. Slightly more than one-third (35 percent) delivered in a health facility. Twenty percent of deliveries occurred in public health facilities, and 15 percent, in private health facilities. Overall, 42 percent of mothers received a postnatal check-up, with 38 percent having the first check-up within two days of delivery (NPC and ICF Macro 2009). Although the use of maternal health services is relatively low, increasing family planning counselling and services addressed to the women who use these services could increase the use of modern methods in the postpartum period.

\section{Data and methods}

The data for this analysis come from the 2008 Nigeria Demographic and Health Survey (NDHS). The survey is a nationally representative sample of 36,800 households. All women of reproductive age (15-49 years) in these households were interviewed, and all men age 15-59 in half of the sampled households were interviewed. This analysis uses only the women's individual recode dataset. The full women's dataset comprises interviews with 33,385 women age 15-49 years. Women were asked about receipt of maternal health care services during their most recent birth only. Therefore, in our analysis women who did not have a live birth in the five years before the survey were excluded from the sample. Also, women whose most recent birth was less than one full year before the date of interview were excluded. This ensures that all women included in the analysis have completed the full 12 months of the postpartum period, and their contraceptive behaviour over the period, as detailed in the calendar data ${ }^{3}$, is been taken into account. A sample of II,499 women was thus generated and used for the analysis presented in this paper.

The outcome variable for the study is use of postpartum family planning ("PPFP"). This is defined as a woman's use of any modern method of contraception during the 12 months following her most recent childbirth, if the birth occurred between January 2003 (base month for collection of calendar data) and at least one full year prior to her interview. Only the most recent birth was considered, even if a woman delivered more than once during the reference period, because the DHS collects some maternal health care information (on antenatal, delivery, and postnatal care) for only the most recent birth. PPFP is dichotomised into I and 0; PPFP is coded I if a woman used any modern method of contraception (pill, IUD, injection, diaphragm, condom (male or female), sterilisation (male or female), implant, or foam/jelly), and coded 0 if otherwise. The Lactational Amenorrhea Method (LAM) was excluded from the modern contraception category, as it is intended for only the first six months after childbirth; its use for the entire 12-month postpartum period is not advisable.

We identified, as the independent variables, four main variables indicating use of maternal health care. These are number of antenatal care visits ("ANC"), whether the woman delivered in a health facility (place of delivery, or "POD"), delivery by a skilled birth attendant ("SBA"), and postnatal care within six weeks of delivery ("PNC"). In addition, a number of control variables were included in the multivariate models; these are mother's age at last childbirth, woman's level of education, household wealth status (measured by the wealth index), place of residence (rural or urban), marital status, region, birth order of the last child, and whether the woman had heard a family planning message in the last few months.

To take into account the differences in the probability of selection as well as to adjust for nonresponse, all tabulations are weighted using the women's sample weight. In addition, to account for the complex sampling design used in DHS data collection, the STATA survey command (svy) was applied in the analysis.

Checking a set of data for the presence of multicollinearity is recommended as a first step in any multiple regression analysis (Mansfield and Helms 1982). While high degrees of correlation between two or more predictor variables in a statistical model may not necessarily reduce the predictive power of the model as a whole (Arceneaux and Huber 2007), collinearity can still pose a problem when estimating

3. Calendar data: the calendar section of DHS surveys are designed to provide a detailed, month-by-month, calendar of events in the five years preceding the interview. These include use of contraception, the specific methods used, and the date when the methods were used, whether the woman combined or switched or discontinued methods, etc. 
the influence of each of the predictor variables on the outcome variable. Such problems include misleading $P$ values, very wide confidence intervals, and the possibility of a false conclusion that there is no linear relationship between a specific predictor and the outcome variable. Our collinearity check shows a high degree of collinearity between POD and SBA. We include POD in the model, but omitted SBA ${ }^{4}$.

The general binary logistic regression model used for the multivariate analyses is:

$$
\log \left(\frac{p}{1-p}\right)=\beta_{0}+\beta_{1} x_{1}+\ldots+\beta_{n} x_{n}
$$

where:

$\mathrm{p} \quad=$ probability of postpartum use of modern contraceptive ( 1 if using, else 0 )

$x_{1}-x_{n}=$ predictor variables (key independent variables (ANC, POD, PNC) and the selected socio-demographic characteristics

$\beta_{0}, \beta_{1}-\beta_{n}=$ regression coefficients

Data Limitations: This paper is based on data obtained from a cross-sectional survey and is thus subject to the general limitations associated with cross-sectional data, especially that the data cannot be used as a basis for establishing causality among the variables and that recall bias may be associated with the retrospective collection of data. Since the outcome variable in this paper was determined using calendar data obtained at the point of interview in 2008 but dating back as far as January 2003, the possibility of recall errors cannot be ruled out. Furthermore, the control variables, including education and marital status, were current status measures in 2008 (date of interview), but were used as controls for postpartum periods stretching from January 2003 up to one full year prior to the date of interview. Also, the 2008 NDHS (like most DHS surveys) used the multi-stage cluster sampling technique. A general limitation of this technique is that it provides less precision than either the simple random sampling or stratified random sampling. However, it is the most economic option if sample is to be drawn from a large population size or wide geographical entity, as is Nigeria. The large sample size used in DHS surveys may however be sufficient to offset the loss in precision.

Additional checks were performed to mitigate the effects of these limitations arising from the nature of the data used. For marital status, we reclassified a currently married woman as never married if her date of first marriage is after her date of last birth (used to determine her postpartum status). The limitation remains that for women who are currently divorced or widowed, it is not known whether they were married at the time of the birth; however these women comprise less than 5 percent of the final sample. Concerning education, only 6 percent of the women in the sample delivered before age 18, hence we think it is reasonable to assume that the current educational status of women with no education, only primary education, or only secondary education was the same at interview as when they gave birth. The most likely change in educational status since the date of the last birth would be among women whose current educational level is post-secondary (7 percent), but this cannot be verified without dates of school attendance, which are not part of the DHS.

Ethical Considerations: Participation in the 2008 NDHS was voluntary, as it is with all DHS surveys. The cartographers who conduct the household listing prior to the survey meet with community leaders prior to the survey being conducted. Prior to commencing data collection in all the different areas of the country, information about the survey is conveyed to possible respondents via radio, television, and print media messages. Consent statements were read to respondents and their consent obtained before the commencement of any interview. The research protocol (including survey instruments) were approved by the National Health Research Ethics Committee in Nigeria.

\section{Results}

Selected Background Characteristics of Respondents: This section presents selected background characteristics for postpartum women, that is, women who had their most recent birth between January 2003 and one full year before the date of interview; only the characteristics used as control variables in the

4. Although delivery care by a skilled birth attendant is an essential component of maternal health care, care by an SBA may not be as important a factor in the use of PPFP as delivery in a health facility (POD). 
multivariate model are described.

The age of the postpartum women at the time that they had their last delivery is shown in Table I. About three of every four women (74 percent) delivered within the age range 18-34 years. The remaining one-quarter delivered at high-risk ages: 6 percent were under 18 years old when they delivered, while one-fifth (20 percent) delivered after their 35th birthdays. A high proportion of the women (45 percent) had no formal education, while 23 percent had attended only primary school. One in every four ( 25 percent) had a secondary school education. Only 7 percent had post-secondary education. As measured by the DHS 5-quintile wealth index, 23 percent of the women were in households in the lowest quintile, and about the same proportion (22 percent) were in the second quintile. Close to one-fifth (19 percent) were in the middle quintile, while about 18 percent each were in the fourth and highest quintiles. A large majority of the women $(93$ percent) were married, while a small proportion (4 percent) were previously married but no longer in union due to divorce, widowhood, or separation. The remaining 3 percent were never married. This underlines the fact that childbearing in Nigeria occurs almost entirely within marital unions. More than two-thirds (69 percent) of the postpartum women were interviewed in rural areas, while the remaining 31 percent were interviewed in the urban areas. The regional distribution of the respondents indicates that 60 percent were in the northern part of the country and 40 percent were in the southern part. The largest number of women (30 percent) were in the North West Zone.

Table I Used modern method within I 2 months following birth, by selected background characteristics Percent distribution of postpartum women age 15-49 in the five years preceding the survey whose most recent birth was at least one full year preceding the survey, and the percentage who used contraception (among postpartum women), by background characteristics, NDHS 2008

\begin{tabular}{|c|c|c|c|}
\hline Background characteristic & $\begin{array}{l}\text { Postpartumwomen } \\
\text { (\%) }\end{array}$ & $\begin{array}{l}\text { Using modern } \\
\text { contraception (\%) }\end{array}$ & $\begin{array}{l}\text { Number of } \\
\text { women }\end{array}$ \\
\hline \multicolumn{4}{|l|}{ Mother's age at last birth } \\
\hline$<18$ years & 5.9 & 2.7 & 679 \\
\hline $18-34$ & 73.7 & 9.2 & 8,473 \\
\hline $35-49$ & 20.4 & 7.5 & 2,347 \\
\hline \multicolumn{4}{|l|}{ Education } \\
\hline No formal education & 45.3 & $\mathrm{I} .4$ & 5,205 \\
\hline Primary & 23.0 & 9.2 & 2,648 \\
\hline Secondary & 25.2 & 16.0 & 2,902 \\
\hline Post-secondary & 6.5 & 25.6 & 744 \\
\hline \multicolumn{4}{|l|}{ Place of residence } \\
\hline Urban & 30.6 & I5. I & 3,513 \\
\hline Rural & 69.4 & 5.5 & 7,986 \\
\hline \multicolumn{4}{|l|}{ Wealth quintile } \\
\hline Lowest & 22.7 & 1.5 & 2,607 \\
\hline Second & 21.8 & 3.1 & 2,508 \\
\hline Middle & 19.2 & 6.0 & 2,208 \\
\hline Fourth & 18.3 & 12.4 & 2,099 \\
\hline Highest & 18.1 & 22.4 & 2,077 \\
\hline \multicolumn{4}{|l|}{ Marital status } \\
\hline Never married & 3.3 & 12.3 & 374 \\
\hline Married & 92.5 & 8.3 & $|0,64|$ \\
\hline Previously married & 4.2 & 8.0 & 484 \\
\hline
\end{tabular}


Region

\begin{tabular}{llll} 
North Central & 14.7 & 8.0 & 1,698 \\
North East & 14.8 & 2.4 & 1,703 \\
North West & 30.4 & 2.8 & 3,490 \\
South East & 8.9 & 11.1 & 1,025 \\
South South & 13.1 & 13.8 & 1,503 \\
South West & 18.1 & 18.1 & 2,080 \\
Birth order & & & 1,815 \\
I & 15.8 & 9.8 & 3,591 \\
2-3 & 31.2 & 9.5 & 2,904 \\
4-5 & 25.3 & 9.8 & 3,190 \\
$6+$ & 27.7 & 5.3 & \\
Religion & & 13.9 & 5,156 \\
Christian & 44.8 & 3.9 & 6,073 \\
Muslim & 52.8 & 5.4 & 269 \\
Others & 2.3 & 8.4 & 11,499 \\
Total & 100.0 & & \\
\hline * Here and throughout the tables, women who were currently married at the time of interview in 2008, but who \\
had their most recent birth before the date of their first marriage were re-classified as never-married.
\end{tabular}

As for the birth order of their last delivery within the study period, 16 percent of births were first-order births; 31 percent of the women were having their second or third births; while more than one-quarter of the women were giving birth to at least their sixth child, underlying the high fertility level in the country. Also, the data showed that more than half of the women $(53 \%)$ were Muslims while $45 \%$ were Christians. Only 2 percent of the respondents were of other beliefs (mainly traditionalists).

Table I also shows the percentage of women who used a method of modern family planning in the postpartum period disaggregated by background characteristics. About the same proportion of women age 18-34 and 35-49 had used a modern method ( 9 percent and 8 percent, respectively), but only 3 percent of women under 18 years of age had used a modern method. Education is directly related to the use of contraception. Only I percent of women with no education had used modern contraceptives postpartum compared with 9 percent of those with primary education and 16 percent of those with secondary education, while one in every four women with post-secondary education (26 percent) had used modern contraception postpartum. As for percent distribution by place and region, 15 percent of the women who were interviewed in urban areas had used modern methods postpartum, compared with 6 percent of those interviewed in rural areas. Postpartum use of modern methods of contraception was lower in the northern regions than in the southern regions. By religion, $14 \%$ of Christians were using a modern method of contraception compared to $4 \%$ of Muslims and $5 \%$ of women of other religions.

Use of Maternal Health Care: Table 2 shows the percent distribution of the postpartum women by their use of maternal health care-number of antenatal care visits, delivery at a health facility, and receiving postnatal care within six weeks of delivery. Noting the importance of the various interventions provided as components of antenatal services, including tetanus toxoid vaccination, screening and treatment of infections, and identifying warning signs of pregnancy complications, the WHO recommends that a woman make at least four antenatal care visits during pregnancy. Disaggregating the postpartum women by the number of antenatal care visits made, we find that less than half of these women ( 43 percent) made the recommended minimum number of four antenatal care visits during their most recent pregnancy. Another 9 percent made one to three antenatal care visits. Almost half (48 percent) reported having no antenatal care visits during their last pregnancy. Only 35 percent of postpartum women whose most recent birth was between January 2003 and one full year before the interview had delivered in a health facility. 
The third main independent variable examined is the timing of postnatal care. Postnatal care is an essential component of maternal health care, as most maternal deaths occur within the first few hours of the postnatal period. It is therefore crucial that routine PNC for all mothers take place immediately after childbirth and at least in the first six weeks. In addition to checking for complications that could result in maternal deaths and morbidity, an essential component of routine PNC is counselling and the offer of a wide range of family planning services. Modifying the WHO's 6-6-6-6 model on the timing of first postnatal visits (six to 12 hours after birth, three to six days, six weeks, and six months) (Sines et al. 2007), this study categorises timing of PNC visits into three groups: no PNC, PNC two days or less after delivery, and PNC from three days to six weeks after delivery. About three in every five postpartum women (60 percent) did not receive PNC at all, 37 percent were examined two days or less after delivery, while the remaining 3 percent had their first PNC visit three days to six weeks after delivery. Finally, for women in our sample who had had at least two births $(N=9,684)$, we looked at the timing between most recent and earlier birth. Onequarter of the women ( 25 percent) had delivered within 24 months of the previous birth, underlying the fact that a sizeable proportion of pregnancies cum births in Nigeria were high-risk.

Use of Postpartum Family Planning: Overall, the calendar data reveal that, over the five years before the survey, only 8.45 percent of the postpartum women had used any modern method of family planning. Of the 8.45 percent who had used a method, almost all (8.32 percent) had used just one method over the period of 12 months following last childbirth. Male condoms were the most widely used method ( 3 percent). About 2 percent each relied on injections and the pill, and about I percent used IUDs.

Use of Maternal Health Care and Postpartum Contraception: We used chi-square tests to gauge the association between each of the three main independent variables and use of modern contraception by postpartum women. The number of antenatal care visits is significantly related to the use of mod- ern contraception $(p<0.01)$; as the number of antenatal care visits increases, the percentage using modern methods of contraception also increases. Only 4 percent of postpartum women who did not have any antenatal care visits during their last pregnancy had used a modern method of contraception postpartum, compared with 7 percent of those with one to three antenatal care visits and 14 percent of those with four or more antenatal care visits. Also, the chi-square result suggests that delivery in a health facility is a statistically significant predictor of modern contraceptive use $(p<0.01)$. Among women who delivered in a health facility, the percentage using a modern method of contraception during the postpartum period ( 15 percent) is thrice the percentage among women who did not deliver in a health facility (5 percent). Similarly, the use and timing of postnatal check-ups is significantly related to the use of modern contraception postpartum $(p<0.0 \mathrm{I})$. Only 5 percent of women who had no PNC after their last birth had used a modern method of contraception during the postpartum period. Postpartum use of a modern method was about three times as great among women whose first PNC took place within two days of delivery or less of giving birth (14 percent) or between three days and six weeks after delivery ( 16 percent). In addition, we tested the bivariate association between the selected control variables (mother's age at birth, marital status, place of residence, region, education, wealth index, birth order, and exposure to family planning messages) and the use of modern method of contraception (outcome variable) among postpartum women. There was a significant bivariate association between all eight characteristics and the four outcome variables.

Table 2 shows the adjusted odds ratios from the multivariate logistic regression analysis of the key independent variables (antenatal care visits, delivered at a heath facility, and postnatal care) on the dependent variable (postpartum use of modern contraception). The model controls for the effects of educational level, wealth index, place of residence, birth order, marital status, region, exposure to family planning messages, and religion on the outcome variable.

Table 2. Odds of using a modern method of contraception during the postpartum period, by number of antenatal visits (ANC), place of delivery (POD) and timing of postnatal visits (PNC)

\begin{tabular}{|c|c|c|c|c|c|c|}
\hline & ANC & & POD & & PNC & \\
\hline & Odds ratio & $95 \% \mathrm{Cl}$ & Odds ratio & $95 \% \mathrm{Cl}$ & Odds ratio & $95 \% \mathrm{Cl}$ \\
\hline
\end{tabular}

Number of ANC visits

$\begin{array}{lll}\text { No visit } & 0.7 \mid * * & 0.582-0.869 \\ \text { I-3 visits } & \text { I.03 } & 0.780-1.37 \text { I } \\ 4+\text { visits } & \text { RC } & \end{array}$


Place of delivery

No

Yes

Timing of postnatal check-up

No PNC

Within 2 days

Between 3 days and 6 weeks

Exposure to family planning messages*

No

Yes

Mother's age at last birth

$<18$ years

18-34 years

35-49 years

Education

No education

Primary

Secondary

Post-secondary

Wealth index

Lowest

Second

Middle

Fourth

Highest

Place of residence

Urban

Rural

RC

0.95

RC

I.38

I. 80 ***

2.65 **

3.58 **

ANC

Odds ratio $\quad 95 \% \mathrm{Cl}$

RC

1.02

1.22

1.25

$6+$

Marital status

Never married

Married

Previously married

Region

North Central

North East

North West

South East

South South

South West

Religion

RC

RC

0.88

I.0I

$0.62 * *$

0.73

0.58*

0.84

RC
RC

I.05 0.868-I.276

$\mathrm{RC}$

I.2I 0.998-I.480

I.73**

I.218-2.466

$\mathrm{RC}$

I.446-2.174 I.80**

I. $470-2.208$

$\mathrm{RC}$

I. $77^{* *}$

I.44I-2.164

$\mathrm{RC}$

0.945-2.925 $\quad 1.67$

$0.950-2.958$

$0.948-2.930 \quad 1.66$

$0.767-2.528 \quad I .40$

$0.77 \mid-2.555$

RC

RC

$2.217-4.444 \quad 3.32 *$

2.344-4.694 3.26**

2.306-4.609 2.550-5.297 3.89**

2.692-5.630 3.8I**

2.643-5.498

3.121-7.210 5.01**

3.282-7.637 4.88**

$3.207-7.416$

$\mathrm{RC}$

0.903-2.III I.43

I.213-2.669 I.89**

0.932-2.182

RC

0.923-2.159

I.273-2.8I I I.85**

1.243-2.749

I.756-3.992 2.78**

I.84|-4.200 2.70**

I.790-4.085

$2.310-5.557 \quad 3.77^{* * *}$

2.426-5.859 3.64**

2.342-5.659

$\mathrm{RC}$

$0.759-I .187 \quad 0.94$

$0.75 I-I .175 \quad 0.94$

$0.753-1.175$

POD

PNC

Odds ratio $\quad 95 \% \mathrm{Cl}$

Odds ratio

$95 \% \mathrm{Cl}$

RC

RC

0.797-I.297 I.0I

$0.789-\mathrm{I} .286 \quad \mathrm{I} .02$

0.795-I.299

0.934-I.590 I.2।

$0.927-1.578 \quad 1.22$

0.935-I.597

$0.925-1.692 \quad 1.24$

$0.913-1.674 \quad 1.26$

0.929-I.704

$\mathrm{RC}$

$\mathrm{RC}$

0.593-1.299 0.91

$0.612-1.339 \quad 0.90$

$0.6|0-1.33|$

$0.469-1.386 \quad 0.82$

$0.477-1.412 \quad 0.82$

0.474-I.409

0.754-I.348 I.02

$0.765-1.369 \quad 1.03$

$0.77|-| .38 \mid$

0.434-0.899

$0.64 *$

0.438-0.937 0.64*

0.443-0.928

$0.44 I-I .223$

0.67

0.4I4-I.I69 0.72

$0.433-1.191$

$0.431-0.775$

$0.56 * *$

0.4I5-0.748 0.57**

0.425-0.77।

0.653-I.086 0.81

$0.638-1.047 \quad 0.8$ ।

0.625-1.039

$\mathrm{RC}$

RC 


\begin{tabular}{|c|c|c|c|c|c|c|}
\hline Christian & $\mathrm{RC}$ & & $\mathrm{RC}$ & & $\mathrm{RC}$ & \\
\hline Muslim & $0.63^{*}$ & $0.462-0.859$ & $0.63 *$ & $0.458-0.857$ & $0.62 *$ & 0.458-0.85I \\
\hline Others & 0.97 & $0.493-1.904$ & 0.97 & $0.490-1.901$ & 0.99 & $0.502-1.942$ \\
\hline
\end{tabular}

Table 2 presents the results of three logistic regression models. In the first model, the number of ANC visits was the only key independent variable included (alongside all the selected control variables). Relative to postpartum women who did not have any ANC visits for their last pregnancy (reference category), the odds of using modern methods of contraception are significantly higher among women who made at least one antenatal care visit. Relative to who had four or more antenatal care visits, the adjusted odds of using a modern method of contraception was not significantly different (I.03) for women who had one to three antenatal care visits; however, among women who had no antenatal care visits, the adjusted odds ratio of using a modern method of contraception is significantly lower (0.7I, p0.00I) than among women who had four or more ANC visits.

In the second logistic regression model, only the place of delivery (POD) was included as a key independent variable. After adjusting for the effects of the selected control variables, POD ceased to be a significant predictor of postpartum modern contraceptive use.

However, among the control variables, education levels are still significant predictors of the use of modern contraception by women in the postpartum period. Women with primary or higher education are at least four times as likely to use modern contraception postpartum as the reference group, postpartum women with no education. Another variable that significantly predicts the use of modern methods of contraception postpartum is the wealth quintile of the woman's household, as measured by the wealth index. The odds of using modern methods increase consistently with higher wealth quintiles.
Another key independent variable influencing use of modern contraceptives methods postpartum is postnatal care within six weeks of childbirth (PNC). Table 2 also presents these results from the third logistic regression model. First receiving postnatal care sometime between three days and six weeks after delivery is significantly related to the postpartum use of modern methods of contraception. The adjusted odds of using a modern method of contraception in the postpartum period are 1.7 times higher among women who received PNC between three days and six weeks after their last delivery, relative to those who did not receive any PNC (reference category). The odds are 1.2 times higher among women who received PNC within two days of their last delivery, but this difference is not statistically significant. Among the control variables exposure to family planning messages, education, the wealth index, and region are significant predictors of postpartum use of modern contraception. In all three models (with each of ANC, POD, PNC as key independent variable), the adjusted odds of using a modern method of contraception during the postpartum period among Muslim women are significantly lower relative to their Christian counterparts.

In the fourth model all three key independent variables - antenatal care visits, delivered at a health facility and receiving postnatal care within six weeks of delivery-are combined to predict the use of modern contraception during the postpartum period. Table 3 presents the results. The control variables remain the same (education, wealth index, place of residence, birth order of the last child, marital status, region, exposure to family planning messages, and religion).

Table 3 Odds of using a modern method of contraception during the postpartum period, by health services: number of ANC visits, place of delivery, and timing of postnatal care

\begin{tabular}{llll}
\hline Variables & Odds ratio & Standard error & $\mathbf{9 5 \%} \mathbf{C l}$ \\
\hline Number of ANC visits & & & \\
\hline No visit & $0.74^{* *}$ & 0.077 & $0.603-0.907$ \\
I-3 visits & 1.05 & 0.150 & $0.789-1.387$ \\
$4+$ visits & RC & & \\
Place of delivery & & & \\
No & RC & & \\
Yes & 0.94 & 0.100 & $0.765-1.161$
\end{tabular}


Timing of postnatal check-up No PNC

RC

Within 2 days

I.16

0.125

$0.938-1.432$

Between 3 days and 6 weeks

$1.60 * *$

0.286

I. $131-2.277$

Exposure to family planning messages

No

$\mathrm{RC}$

Yes

I. $75 * *$

0.182

$1.428-2.146$

Mother's age at last birth

$<18$ years

$\mathrm{RC}$

18-34 years

1.68

0.486

$0.952-2.963$

35-49 years

1.42

0.433

$0.781-2.585$

Education

No education

RC

Primary

$3.13 * *$

0.549

2.216-4.4I5

Secondary

3.66**

0.675

2.550-5.257

Post-secondary

$4.72 * *$

1.001

3.118-7.162

Wealth index

Lowest

RC

Second

I. 38

0.299

$0.902-2.110$

Middle

I.79**

0.360

$1.203-2.653$

Fourth

2.63**

0.551

1.744-3.967

Highest

$3.55 * *$

0.801

2.279-5.528

Place of residence

Urban

$\mathrm{RC}$

Rural

0.95

0.108

$0.759-1.185$

Birth order

I

RC

2-3

1.02

0.128

0.800-I.307

4-5

1.22

0.167

0.938-1.602

$6+$

1.27

0.196

0.934-I.7I5

Marital status

Never married

$\mathrm{RC}$

Married

0.88

0.177

0.595-I.306

Previously married

0.81

0.224

$0.469-1.393$

Contd.

Variables

Odds ratio

Standard error

$95 \% \mathrm{Cl}$

Region

North Central

1.02

0.151

0.759-1.359

North East

0.63*

0.118

0.432-0.907

North West

0.74

0.195

0.442-I.244

South East

$0.59 * *$

0.091

0.434-0.798

South South

0.83

0.107

0.644-|.07|

South West

RC

Religion

Christian

RC

Muslim

$0.63^{* *}$

0.989

$0.461-0.856$

Others

0.98

0.340

0.500-1.939

Heard at least one family planning message in the last few months

$\mathrm{Cl}=$ confidence interval; $\mathrm{RC}=$ reference category; $\mathrm{ANC}=$ antenatal care; $\mathrm{PNC}=$ postnatal care Level of significance: ${ }^{*} \mathrm{p}<0.05$; ** $\mathrm{p}<0.00$ I 
In this fourth model, ANC remains a significant predictor of the use of modern contraception postpartum. Relative to women who made four or more antenatal care visits during their last pregnancy, the odds of using modern contraception in the postpartum period are significantly lower for women who did not make any antenatal care visits during their last pregnancy. Similarly, receiving PNC is a significant predictor of postpartum contraception. Receiving PNC between three days and six weeks after delivery is significantly related to postpartum use of modern contraception when compared with women who had no PNC check-up after their last delivery.

\section{Discussion and conclusion}

This study examines the effect of maternal health care (ANC visits, delivery in health facilities, and timing of the first postnatal check-up) on use of modern methods of contraception in the postpartum period. Slightly more than two-fifths of the postpartum women (43 percent) had the WHO-recommended four or more antenatal care visits for their most recent birth. More than one-third (35 percent) delivered in a health facility. Only 40 percent of the women received a postnatal check-up within six weeks after last childbirth. The proportion of postpartum women who used a modern method of contraception within the 12 months following last delivery was very low (8 percent). Among users of modern contraceptives, 3 percent had used male condoms, 2 percent each had used pills and injectables, and about I percent had used IUDs or female sterilisation. A sizeable proportion of births in the country in the five years before the survey were high-risk births; more than one-quarter of the most recent births were the sixth or more. One-quarter of the births occurred within 24 months of the previous birth. This suggests that one-quarter of the women had become pregnant again about a year after giving birth. For Nigeria, a country with the second highest number of maternal deaths in the world (WHO 20I0), the combination of low contraceptive use, high-risk pregnancies, and many women's lack of maternal health care poses a considerable challenge to realisation of the MDG 5 goals of improving maternal health.

The findings show that the use of a modern method of contraception during the postpartum period is significantly associated with use of maternal health care (ANC visits and timing of postnatal check-up), even after controlling for other factors associated with the use of family planning. This relationship is consistent with findings reported by other studies (Barber 2007, Hotchkiss et al. 2005). The findings suggest that antenatal and postnatal services remain important windows of opportunity to provide access to family planning messages and to offer women various contraceptive methods. Apart from the maternal health services, other significant predictors of the use of contraception in the postpartum period include region, education, the wealth index, exposure to family planning messages, and religion. That religion (being Muslim) is significantly associated with lower odds of modern contraceptive use among postpartum women, relative to being Christian, underlies the need to involve Islamic clerics and opinion leaders in the efforts to make pregnancy and childbirth safer through the use of family planning in the critical postpartum periods. (Tawiah 20II) having found that among Muslim women, 85 percent of husbands/partner make decisions on healthcare for the woman compared to 7.9 percent of respondents themselves making the decision, remarked that the situation in Nigeria has serious implications for maternal health care.

Also, the findings that education and wealth index are significant predictors of postpartum contraceptive use highlight the need to empower women through education and economic opportunities to be able to make informed choices. These findings are not novel, as research has consistently shown that better educated, wealthier women, women who live in urban areas, and women who were regularly exposed to the media are all more likely to use contraception in the postpartum period (Gebreselassie et al. 2008, Do and Hotchkiss 20II).

The place of delivery was not found to be a significant predictor of the use of modern contraception in the postpartum period. This finding contrasts with those of some similar research in Mexico, which reported that women who delivered in government or private facilities were more likely to use a contraceptive method postpartum than those who delivered at home (Barber 2007). In spite of the very low rate of contraceptive use in the country, a recently published study estimates that contraceptive use averted about I.4 million births in Nigeria in 2008 and an estimated 17,227 maternal deaths. But for contraception, maternal deaths in Nigeria would have been around 66,099 rather than the estimated 48,872 deaths that year (Ahmed et al. 20I2).

Although DHS data cannot show the extent of integration between family planning services and maternal healthcare, it is likely that further integration of these services would help increase the uptake of modern family planning during the critical postpartum period. While the proportion of women using maternal health care (antenatal, delivery or postnatal) is still low in the country, the significant association between the use of maternal health care and adoption of a modern method of contraception 
within a year of childbirth suggests that if more women use these maternal health care, Nigeria's modern contraceptive prevalence (which at present is only 10\% (NPC and ICF Macro 2009)) will increase. The findings indicate that contraceptive use among postpartum women will significantly increase if more women use maternal health care services, especially for antenatal care and postnatal care. In addition to the documented benefits of antenatal care and postnatal check-ups on maternal and child health, they appear to also increase the use of postpartum family planning. Finally, while recommending the intensification of efforts on the integration of family planning services with maternal health care services, stakeholders should also recognise that the proportion of women using maternal health care in the country is quite low, there should therefore be a major drive towards increasing the usage, similar to immunization and polio eradication campaigns.

\section{Acknowledgements}

The authors acknowledge the financial support provided for this research by the United States Agency for International Development (USAID) through the MEASURE DHS project (\#GPO-C-00-08-00008$00)$. The views expressed are those of the authors and do not necessarily reflect the views of USAID or the United States Government. The authors also acknowledge the contributions of Sarah Staveteig and Wenjuan Wang of the MEASURE DHS Project, ICF International, for training on the analysis of DHS data and supervising the analysis and report writing; Sarah also helped to generate the STATA codes for analyzing the calendar data, and Wenjuan helped with the codes on timing of first postnatal care. We also acknowledge the contributions of Jupiter Simbeye, Peninah Masibo, Helen Namirembe-Nviiri, and our co-fellows (the 2012 DHS Fellowship cohort) during presentations and discussions of our work. Finally, we thank Fred Arnold (ICF International), and Francis Kundu (NCPD, Nairobi) who reviewed and offered valuable feedback on our drafts, as well as Bryant Robey for editing and Yuan Cheng for formatting the paper.

\section{References}

Ahmed, S., Li, Q., Liu, L. and Tsui, A. O. (20I2)

'Maternal deaths averted by contraceptive use: an analysis of 172 countries', The Lancet, 380(9837), III-125.

Arceneaux, K. and Huber, G. A. (2007) 'What to Do (And Not Do) with Multicollinearity in State Politics Research', State Politics \& Policy Quarterly, 7(I), 8I-I0I.

Barber, S. L. (2007) 'Family planning advice and postpartum contraceptive use among lowincome women in Mexico', International Family Planning Perspectives, 6-12.

Borda, M., Winfrey, W. and McKaig, C. (2010) 'Return to Sexual Activity and Modern Family Planning Use in the Extended Postpartum Period: An Analysis of Findings from Seventeen Countries', African Journal of Reproductive Health, (14), 75-82.

Do, M. and Hotchkiss, D. (20II) 'Relationships between Maternal Health Care and Postpartum Modern Contraceptive Use in Kenya and Zambia', Working Paper(I20),

Gebreselassie, T., Rutstein, S. O. and Mishra, V. (2008) Contraceptive use, breastfeeding, amenorrhea and abstinence during the postpartum period: An analysis of four countries, Marco International.

Hotchkiss, D. R., Rous, J. J., Seiber, E. E. and Berruti, A. A. (2005) 'Is maternal and child health service use a causal gateway to subsequent contraceptive use?: A multi-country study', Population Research and Policy Review, 24(6), 543-57I.

Laukaran, V. H. and Winikoff, B. (1985)

'Contraceptive use, amenorrhea, and breastfeeding in postpartum women', Studies in Family Planning, 16(6), 293-30I.

Lawan, M. M. (20I2) 'Statement of the Senate Chairman, Committee on Population on 7 Billion World Population Day',

Lawrence, F. (20I2) 'Nigeria's population hits 167 million mark', The Guardian (Nigeria), October 27, 2012,

Mansfield, E. R. and Helms, B. P. (1982) 'Detecting Multicollinearity', The American Statistician, 36(3), I58-160.

NPC, N. P. C. and ICF Macro (2009) Nigeria Demographic and Health Survey 2008, Abuja, Nigeria: National Population Commission, Nigeria and ICF Macro.

Olokor, F. (2012) 'I67 million people live in NigeriaNPC', The Punch, August 5, 20I2,

Ringheim, K. (20II) 'Integrating Family Planning and Maternal and Child Health Services: History Reveals a Winning Combination',

Ross, J. A. and Winfrey, W. L. (200 I) 'Contraceptive use, intention to use and unmet need during the extended postpartum period', International Family Planning Perspectives, 20-27.

Sines, E., Syed, U., Wall, S. and Worley, H. (2007) 'Postnatal care: A critical opportunity to save mothers and newborns', Policy Perspectives on Newborn Health.

Tawiah, E. O. (20II) 'Maternal Health Care in Five sub-Saharan African Countries', African Population Studies, 25(I). 
Taylor, H. C. and Berelson, B. (197I)

'Comprehensive family planning based on maternal-child health services: a feasibility study for a world program', Studies in Family Planning, 2(2), I.

Vernon, R. (2009) 'Meeting the family planning needs of postpartum women', Studies in Family Planning, 40(3), 235-245.

WHO, W. H. O. (2010) Trends in Maternal Mortality:
1990-2008. Estimates Developed by WHO/ UNICEF/UNFPA and The World Bank, World Health Organization [online], available: $h t t p: / /$ whqlibdoc.who.int/publications/2010/ 978924/500265_eng.pdf [accessed

Zerai, A. and Tsui, A. O. (200I) 'The Relationship between Prenatal Care and Subsequent Modern Contraceptive Use in Bolivia, Egypt and Thailand', African Journal of Reproductive Health, 68-82. 